\title{
SEISMIC HAZARD ASSESSMENT IN THE BROADER AEGEAN AREA USING TIME-INDEPENDENT SEISMICITY MODELS BASED ON SYNTHETIC EARTHQUAKE CATALOGS
}

\author{
Vamvakaris D.A. ${ }^{1}$, Papazachos C.B. ${ }^{1}$, Papaioannou Ch.A. ${ }^{2}$, Scordilis E.M. ${ }^{1}$ \\ and Karakaisis G.F. ${ }^{1}$ \\ ${ }^{1}$ Aristotle University of Thessaloniki, Geophysical Laboratory, 54124, Thessaloniki, Greece, \\ dom@geo.auth.gr,kpapaza@geo.auth.gr.manolis@geo.auth.gr,karakais@geo.auth.gr \\ 2'I.T.S.A.K. P.O. Box 53 Foinikas 55102 Thessaloniki-Greece, chpapai@itsak.gr
}

\begin{abstract}
In order to evaluate the seismic hazard for the broader Aegean area, a modified timeindependent seismicity model is used. A Monte-Carlo procedure has been employed to create synthetic earthquake catalogs with specific characteristics regarding their time, space and magnitude distributions. Moreover, particular geometrical characteristics, such as subducting and oblique seismic zones are also taken into account in the synthetic catalogs generation. A significantly revised earthquake catalog, all available fault plane solutions and information on the seismotectonics of the broader Aegean area were considered in order to propose a new updated model of seismic zones for this area. Seismicity parameters for the new seismic zones were calculated and the corresponding synthetic earthquake catalogs were generated using the proposed procedure. The distribution of the expected values for ground motion parameters (e.g. PGA, PGV) was estimated using synthetic catalogs for several sites of interest, by performing computations directly on all earthquakes of each catalog. Computations were performed for a dense grid of sites and seismic hazard estimates were determined both directly from the peak ground motion distribution, as well as from fitted extreme values Gumbel distribution. Ground motion parameters were also calculated using classic seismic hazard assessment algorithms (EqRISK), in order to evaluate the compatibility of the proposed method with conventional approaches.
\end{abstract}

Keywords: seismic hazard, synthetic catalogs, zonation model.

\section{Пєрі́ $\eta \psi \eta$}

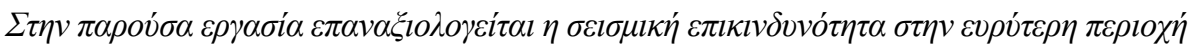

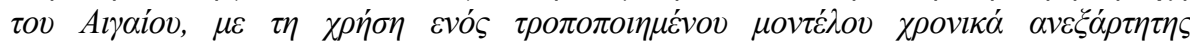

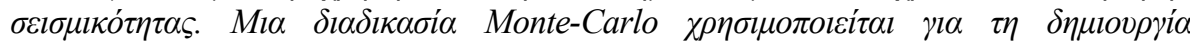

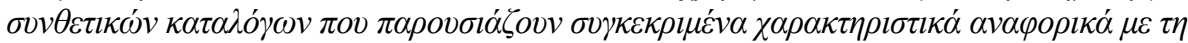

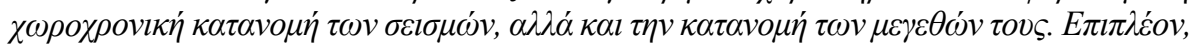

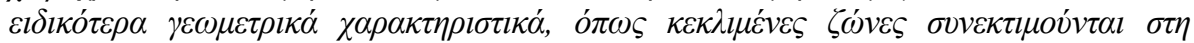

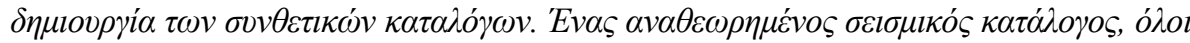

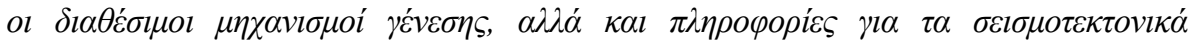

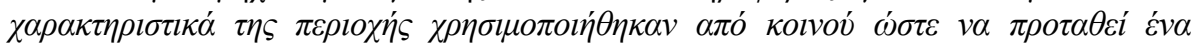

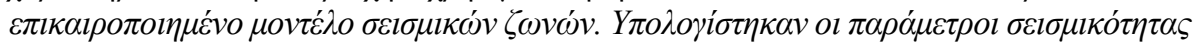




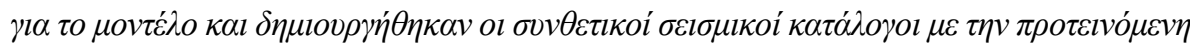

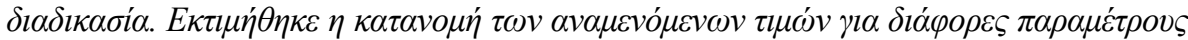

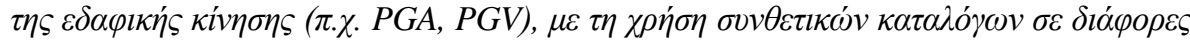

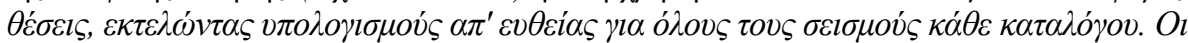

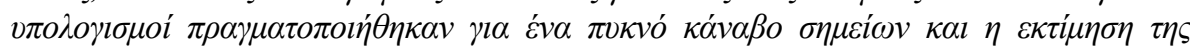

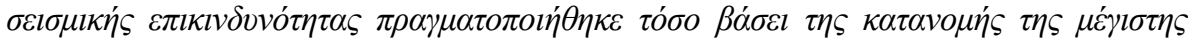

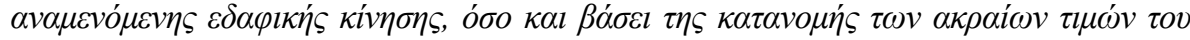

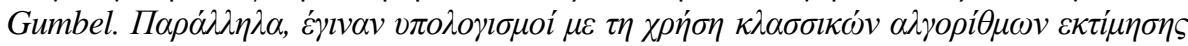

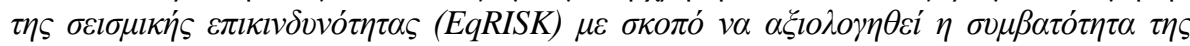

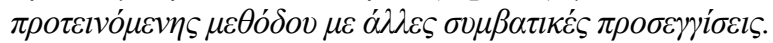

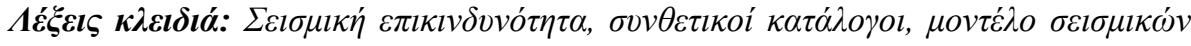
$\zeta \omega v \omega ́ v$.

\section{Introduction}

A large number of research works on seismic hazard assessment for the Aegean area has been published during the last decades. The first effort was performed by Galanopoulos and Delibasis (1972), who studied the maximum expected macroseismic intensity distribution in order to estimate the seismic hazard in Greece, while Shebalin et al. (1976) published a similar study for the Balkan peninsula. Several other studies were performed for the broader Aegean area (Algermissen et al., 1976; Makropoulos and Burton, 1985; Drakopoulos and Stavrakakis, 1988; Papoulia and Stavrakakis, 1990; Koutrakis et al., 2002; Tsapanos et al., 2003; Vamvakaris et al., 2008; Tselentis and Danciu, 2010; Vamvakaris, 2010, among others). Papaioannou (1984), studied $\mathrm{I}_{\mathrm{MM}}$ and PGA using the mean value method (Wiechert and Milne, 1979) and the asymptotic distribution of extreme values (Gumbel, 1958). Stavrakakis and Tselentis (1987), Papoulia and Slejko (1992), Stavrakakis and Drakopoulos (1995) and Papoulia et al. (1998) employed the Bayes distribution, while Papazachos et al. (1993) determined seismic sources for Greece and proposed 4 zones of equal seismic hazard, based on historical data. Additionally, PGD, strong motion duration and velocity spectra values were used for seismic hazard estimation (Theodulidis and Papazachos, 1992; Papazachos et al., 1993; Margaris and Papazachos, 1994; Koutrakis et al., 1999). Papaioannou and Papazachos (2000), reported the expected values of PGA, PGV and $\mathrm{I}_{\mathrm{MM}}$, for 143 sites and proposed a new seismic regionalization for the broader Aegean area.

In the present study a time-independent seismicity model is used for the seismic hazard analysis in terms of parameters such as peak ground acceleration (PGA) and peak ground velocity (PGV). The estimation is based on synthetic earthquake catalogs created through an appropriate procedure employing a Monte-Carlo statistical simulation. Using the proposed approach, earthquakes follow pre-determined time, space and magnitude distributions. Moreover, any particular geometrical characteristic, such as subducting and oblique seismic zones are also taken into account in the synthetic catalogs. These catalogs are used to estimate the statistical distribution of the ground motion parameters for several sites of interest, by performing computations directly on all earthquakes of each catalog. The study area (broader Aegean sea region) contains Greece, Albania, FYROM and parts of Montenegro, Bulgaria, and Turkey, constituting the main part of the Eurasia plate at the region of convergence with the Eastern Mediterranean (Figure 1).

\section{Method}

\subsection{New Seismic Zone Model}

Estimation of seismic hazard parameter, Y, (such as IMM, PGA, PGV, PGD, or their spectral values) practically corresponds to the calculation of the corresponding probability of exceedance, $\mathrm{P}$, of this value in a specific time period. Calculation of this probability is often performed on the basis of the "total probability theorem", expressed by the equation: 
$P(Y>y)=\int_{R} \int_{M} P(Y>y \mid m, r) f(r) f(m) d m d r$

where the probability $P(Y>y)$ is calculated as an integral over magnitude, $m$, and distance, $r$, of the conditional probability $P(Y>y \mid m, r)$, related with the ground motion prediction equation, and probability-density function of magnitude and distance, $f(m)$ and $f(r)$, respectively. These functions describe the magnitude and space distribution of each event participating in the hazard assessment. Earthquake magnitudes define the seismicity level, usually described by $a$ and $b$ seismic parameters, as well as epicenter location is related to the spatial distribution of earthquakes, according to local seismotectonic, geometric and other geomorphological settings.

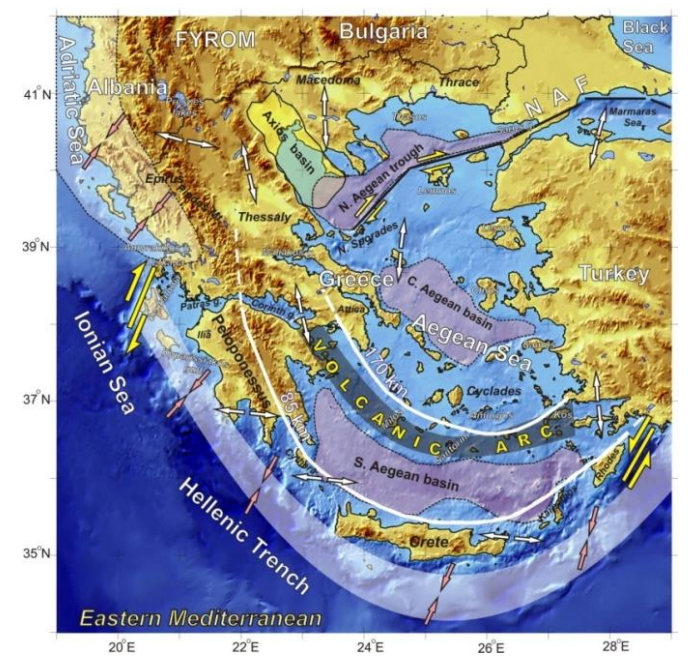

Figure 1 - Map of the study area showing the main seismotectonic features. Open arrows depict the local stress, while the volcanic arc of southern Aegean, the Benioff zone isodepths (white lines), and major basins are also presented (modified from Papazachos et al., 1998; Karagianni et al., 2005 and Mountrakis et al., 2012).

Seismic hazard calculations using algorithms such as EqRISK (McGuire, 1976) are usually based on the use of a seismic zonation model or other tectonic features (e.g. faults and rupture zones) and the computation of hazard probabilities through analytical or numerical integrations. In the present work we use an alternative approach for seismic hazard analysis, based on synthetic earthquake catalogs which satisfy several specific characteristics, concerning the location and geometric features of seismic sources. The proposed approach also allows the parametric study of all seismic hazard estimates simulating different desirable seismic scenarios (extreme or more possible scenarios). As previously described, seismicity is commonly defined as a function of earthquake magnitudes and frequency of occurrence of events with such a magnitude, according to the magnitude distribution law (Gutenberg and Richter, 1944). However, such a relation can only be applied for areas with similar seismotectonic settings. For this reason, the study area needs to be separated to relatively homogeneous seismic zones with common characteristics. Several researchers have worked on the seismic zonation problem in the past for the Aegean area (Papazachos, 1980, 1990; Hadtzidimitriou et al., 1985; Papazachos and Papaioannou, 1993; Papaioannou and Papazachos, 2000). Recently, important information about active neotectonic faults (Mountrakis et al., 2010) and seismic faults related with large earthquakes (Papazachos et al., 2001), as well as the need of a more detailed and specific definition of seismic zones, have led to a new updated model of seismic zones for Greece and neighbouring areas (Vamvakaris, 2010; Vamvakaris et al., 2015). Vamvakaris (2010), collected all available fault plane solutions from international databases and publications and the corresponding stress axes. Information about tectonic and seismic faults and various morphotectonic settings (e.g. relief, coastline) and epicentres of earthquakes since historical times (550BC-July 2008) from the catalog of Papazachos et al. (2010), used in order to define areas of common seismotectonic characteristics, that could constitute a discrete seismic zone. 


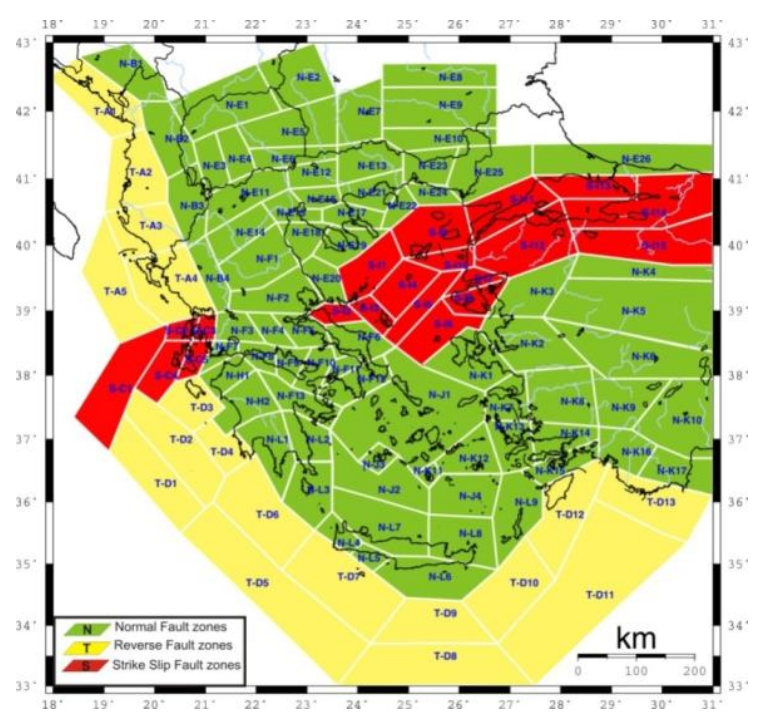

Figure 2 - Map of the 113 shallow seismic zones grouped in 3 general seismotectonic clusters. Yellow colours depict zones related with reverse ruptures (T-cluster), green with normal faulting (N-cluster) and red with strike-slip faults (S-cluster), (Vamvakaris et al., 2015).

Following this approach, the broader area of Aegean has been separated into 113 seismic zones with common seismotectonic features. The new seismic zonation map proposed by Vamvakaris et al. (2015), is presented in Figure 2, These seismic zones exhibit several common characteristics and it is possible to provide a general grouping of the individual zones in 3 main clusters of zones ( $T, N$ and $\mathrm{S}$ clusters) according to the dominant rupture type within each zone (thrust, normal and strikeslip faultings, respectively.

Seismic hazard is strongly related with the seismicity level in any area of interest. The magnitude distribution law (Gutenberg and Richter, 1944) and the random temporal distribution hypothesis (Poisson distribution) are the usual base on which most of the seismicity parameters are defined. In order to estimate $a$ and $b$ parameters of G-R relation for every seismic source it is necessary to employ a homogeneous and complete earthquake catalog, covering the study area. For this reason the a compiled catalog (Vamvakaris, 2010), which was based on the catalog of Papazachos et al. (2010) and ISC, as well as revised equivalent moment magnitude estimations was used.

Using this catalog and its associated completeness a quantitative estimation of seismicity was performed for parameters $a$ and $b$ as well as the maximum magnitude, Mmax, of every seismic zone (Vamvakaris et al., 2015). In Figure 3 the return period for earthquakes with $\mathrm{M} \geq 6.0$ for an area of $10000 \mathrm{~km}^{2}$ is presented, using the determined seismicity parameters for these 113 shallow zones taken into account for the calculations. The results show that minimum return period values $(\operatorname{Tm}<5$ years) are observed in the central Ionian Sea region, e.g. at least one earthquake of magnitude $M \geq 6.0$ occur every 5 years in an area of $10000 \mathrm{~km}^{2}$ in the Cephalonia region.

\subsection{Synthetic Catalogs for the Study Area}

For the seismic hazard assessment synthetic earthquake catalogs were created through a procedure of a Monte-Carlo statistical simulation, employing appropriate random number generation. These catalogs were designed to contain events randomly distributed in time (Poisson distribution), while the probability of occurrence is constant within each seismic zone (homogeneous distribution). A spatial and magnitude distribution follow the Gutenberg-Richter law, specified controlled by the $a$ and $b$ parameters for every seismic zone. For the catalog generation, the new model of 113 shallow seismic zones was complemented by the model of 7 seismic zones proposed by Papazachos and Papaioannou (1993), for intermediate-depth earthquakes. For the present study, a number of 100 synthetic catalogs 
were generated, covering a time period of 1000 years. A typical random synthetic catalog is presented in (Figure 4a), where epicenters of different focal depth are shown with different colours (yellow, pink and red). The epicenter distribution illustrates the dominant effect of the selected seismic model, as well as the depth distribution along a specific SW-NE cross-section (Figure 4b) which exhibits a realistic focal depth distribution. The Benioff zone is clearly recognized in both the map and the crosssection, verifying the proper synthetic catalog generation.

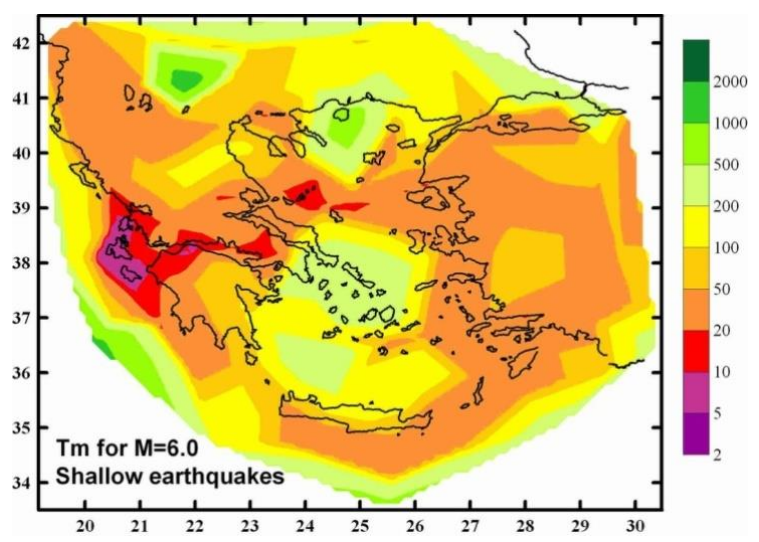

Figure 3 - Spatial distribution of mean return period values, Tm, for shallow earthquakes of magnitude $M \geq 6.0$, for an area of $10000 \mathrm{~km}^{2}(100 \times 100 \mathrm{~km})$, (Vamvakaris et al., 2015).

\section{Seismic Hazard Assessment}

\subsection{Method Application}

In the present study, seismic hazard was determined in terms of peak ground acceleration (PGA) and velocity (PGV), using different ground motion prediction equations, depending on the type of earthquake (shallow/deep, normal/thrust/strike slip). Calculations for PGA were performed using the equation of Skarlatoudis et al. (2003), for shallow earthquakes:

$\log P G A=1.07+0.45 M-1.35 \log (R+6)+0.09 F+0.06 S \pm 0.28$

where $M$ is the earthquake magnitude, $R$ is the epicentral distance, $F$ is a factor related with the rupture type ( $F=0$ for normal and $F=1$ for thrust or strike slip ruptures) and $S$ is a soil condition factor ( $S=1$ for alluvial and $S=0$ for rock).

For intermediate depth earthquakes $(h>60 \mathrm{~km})$ the ground motion prediction equation proposed by Atkinson and Boore (2003), was used:

$\log P G A=0.04713+0.6909 M+0.0113 h+0.00202 R-g \log (R) \pm 0.27$

where $h$ is the depth, $R$ is equal to $\sqrt{D_{\text {fault }}^{2}+\Delta^{2}}, D_{\text {fault }}$ is the hypocentral distance, $\Delta=0.0074 \times 10^{0.507 M}$ and $\mathrm{g}=10^{(0.301-0.01 M)}$.

PGV calculations for shallow earthquakes were performed using the equation proposed by Skarlatoudis et al. (2003, 2007):

$\log P G V=-1.46+0.64 M-1.29 \log (R+6)+0.02 F+0.14 S \pm 0.32$

where the involved parameters are similar to equation (3). For intermediate depth earthquakes, calculations were performed using the equation:

$\log F A S=c_{1}+c_{2} M+c_{21}\left[\log \frac{R}{R_{R E F}}-H\left(R-R_{0}\right) \log \frac{R}{\mathrm{R}_{0}}\right]+$
$+c_{22} \mathrm{H}\left(R-R_{0}\right) \log \frac{R}{R_{0}}+c_{31}(1-\mathrm{ARC})\left(R-R_{R E F}\right)+c_{32} \mathrm{ARC}\left(R-R_{R E F}\right)+c_{41} S_{1}+c_{42} S_{2} \pm \sigma(5)$ 
proposed by Boore et al (2009) using data from the large Kythera earthquake (8/1/2006, M=6.7) for horizontal Fourier acceleration spectrum (FAS), as well as PGA or PGV computations. In this equation, $H\left(R-R_{0}\right)$ is the Heaviside function when the hypocentral distance, $R$, is less or greater than $200 \mathrm{~km}$, respectively, $R_{0}=200 \mathrm{~km}, R_{R E F}=1 \mathrm{~km}, A R C=0$ or 1 for back-arc and along-arc stations, respectively and $S_{I}=1$ and $S_{2}=1$ for soil and soft-soil sites, respectively (and 0 otherwise). The remaining parameters were determined by Skarlatoudis et al. (2013), for PGV calculations: $c_{1}=-$ $4.65517, c_{2}=1.10432, c_{21}=-1.0, c_{22}=-0.5, c_{31}=-0.00315, c_{32}=-0.00223, c_{41}=0.18425, c_{42}=0.50588$, while corresponding standard deviation is $\sigma=0.343$.

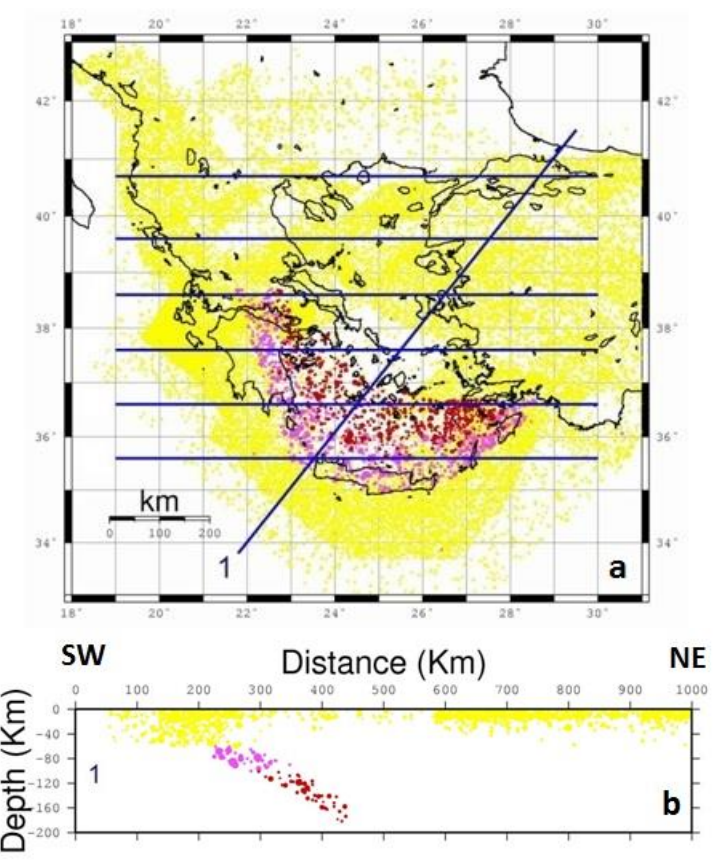

Figure 4 - (a) Geographical distribution of epicentres of a random synthetic catalog with $M \geq 4.5$. - (b) A SW-NE cross section using the synthetic catalog. Shallow depth earthquakes are shown with yellow circles, while pink and red circles correspond to intermediate-depth earthquakes $(60-100 \mathrm{~km}$ and $100-180 \mathrm{~km}$, respectively).

The statistical distribution of the expected values of ground motion parameters (PGA and PGV) for a dense grid of 2080 sites in broader Aegean area was estimated using the synthetic catalogs. Computations were performed directly for each earthquake of every synthetic catalog separately. The maximum value of PGA and PGV was used for each site and every catalog and a set of 100 maximum values was finally available for each examined site. Histograms of the maximum PGA values were plotted with a common axis (Figure 5) for a selected site in the high seismicity Cephalonia area, for 4 different characteristic return periods (10, 20, 50 and 476 years) corresponding to a $2 \%, 4 \%, 10 \%$ and $63.2 \%$ probability of exceedance using 100 synthetic catalos. This distribution follows the asymptotic curve of extreme values (Gumbel, 1958) which is superimposed over the maximum values histogram. Several tests (Vamvakaris, 2010) showed that the PGA values calculated directly from the maximum values histogram correspondig to the values of $98 \%, 96 \%, 90 \%$ and $36.7 \%$ of the values population, respectively) are in a very good agreement with the results provided by the Gumbel distribution. Therefore, the seismic hazard parameters can be estimated alternatively using the fitted Gumbel asymptotic curve. This approach was employed for the final calculation of seismic hazard parameters in the present study. 


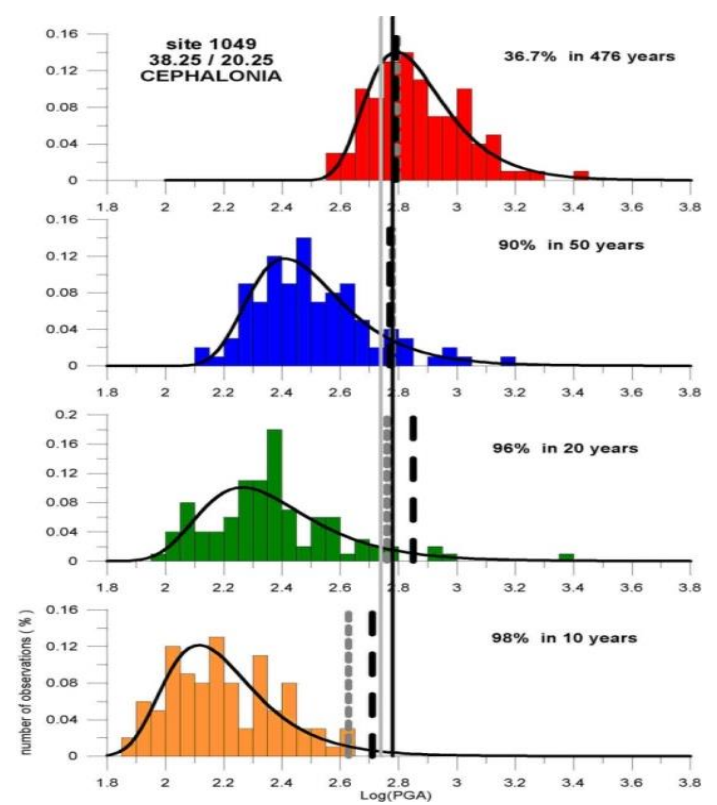

Figure 6 - Combined histograms of maximum PGA values based on observed data for a selected site (Cephalonia area). The Gumbel asymptotic curve of extreme values is also fitted on the data. PGA values were computed directly from 100 synthetic catalogs for 4 different return period (10, 20, 50 and 476 years), as well as the extreme values distribution, (gray and black dashed lines, respectively). Continues gray and black lines shows the mean values of $\log ($ PGA) for the 2 different methods, respectively. (modified by Vamvakaris, 2010)

In Figure 6 the expected values for PGA (left) and PGV (right) are shown for a $63.2 \%$ probability of exceedance for a characteristic return period of 476 years. The spatial distribution of these values shows several similarities and differences. Both maps verify that there is a significant dependence of seismic hazard on the seismotectonic settings. For example, regions along the Hellenic Arc and the North Aegean Trough related with thrust and strike-slip ruptures exhibit high values for both PGA and PGV.

Maximum PGA values are found for the central Ionian Sea area, where the expected ground motion acceleration values reach $0.6 \mathrm{~g}$. High PGA values are also observed around the west coastline of Montenegro, Albania and N. Greece, where dominant thrust rupture zones are observed, similar to the Hellenic arc, where PGA values range between $0.3-0.4 \mathrm{~g}$. Similar values are observed in areas around the N. Anatolia fault, N. Aegean and the Sea of Marmara. Finally, values $0.35 \mathrm{~g}$ are expected for the broader area of Gulf of Corinth.

The spatial distribution of the expected PGV values highlights different areas with the highest values of seismic hazard. The broader area of S. Aegean exhibits high PGV values (locally more than 30 $\mathrm{cm} / \mathrm{sec}$ ), which are much higher than those expected e.g. for the central Ionian Sea. This pattern is obviously related with the subduction zone and the intermediate depth earthquakes which occur in the southern Aegean area, as the PGV attenuation relation results in relatively high values caused by large intermediate depth $(\mathrm{h}>60 \mathrm{~km})$ earthquakes. This pattern is only identified for large return periods ( $\geq 200$ years), because large intermediate depth earthquakes are quite rare. It is interesting to notice that their small frequency of occurrence leads to much smaller PGV values for the S. Aegean for shorter return period calculations ( $\leq 100$ years).

\subsection{Method Evaluation}

Ground motion parameters were also calculated with a classic seismic hazard analysis algorithm, namely EqRISK (McGuire, 1976), in order to evaluate the compatibility of the proposed approach 
of synthetic catalogs, with conventional methods. Results are in a very good agreement regarding both their values, as well as their spatial distribution. This agreement is important of the reliable use of synthetic catalogs for seismic hazard assessment. A detailed study for the broader S. Aegean area shows that the PGA values for the 476 years return period from EqRISK appear to be of about 5$8 \%$ larger than the proposed method using synthetic catalogs (Figure 7). This variation is mainly caused by the different depth distribution adopted of the two methods and especially to the oblique Benioff zone adopted for the generation of intermediate depth earthquakes in the synthetic catalogs, as EqRISK considers horizontal seismic sources at different depths, while the synthetic catalogs approach considers a realistic depth geometry, simulating the oblique Benioff zone for intermediate depth earthquakes and using a different probabilistic distribution in depth, for shallow earthquakes.
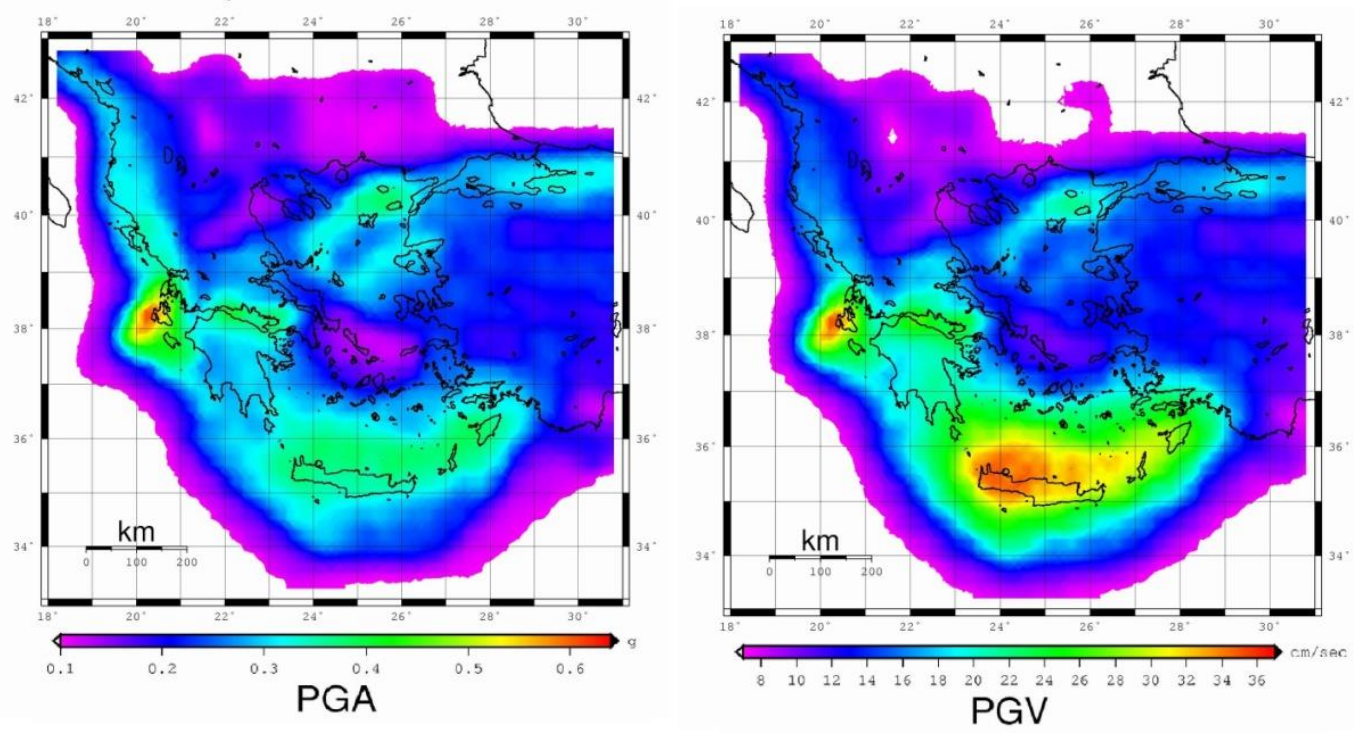

Figure 6 - (Left): PGA distribution (in \%g). - (Right): PGV distribution (in cm/sec). All Calculations were for a 476 years return period, with $63.2 \%$ probability of exceedance.

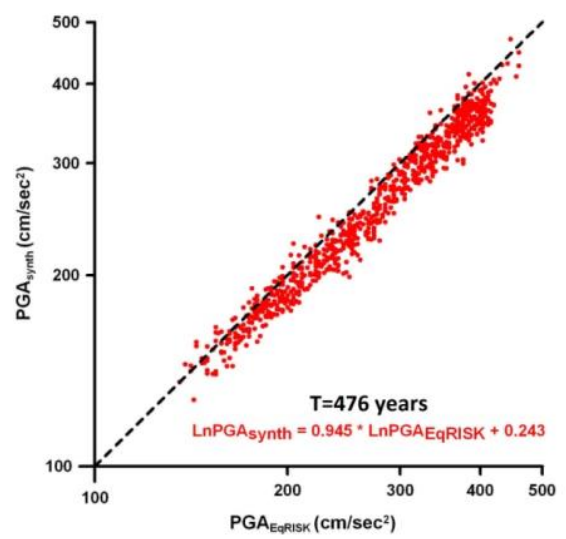

Figure 7 - Comparison of the PGA values resulting from the two different approaches (EqRISK and synthetic catalogs approach). Calculations were made for $T=476$ years.

\section{Conclusions - Results}

A seismic hazard analysis was performed using a new method which is based on the use of synthetic earthquake catalogs, created by a Monte-Carlo procedure. The use of such catalogs appears to have 
several advantages, as it is possible to simulate any preferable seismic source and Ground Motion Prediction Equation scenario. A modified seismic zonation model for 113 shallow seismic zones of the broader Aegean area by Vamvakaris et al. (2015), was used, considering all available information about fault plane solutions, principal stress axes, seismic and neotectonic faults and earthquake epicentres. Seismicity parameters such as $a, b$, Mmax and the corresponding catalog completeness were employed for each one of these seismic zones and used in subsequent hazard analysis. A time-independent seismicity model, assuming a Poisson distribution was used for the creation of synthetic catalogs, which were employed for the computations of seismic hazard. Results are in a good agreement with standard hazard assessment algorithms, such as EqRISK and reveal new features for the distribution of seismic hazard values in the broader Aegean area.

\section{Acknowledgments}

This work was supported by the THALES Program of the Ministry of Education of Greece and the European Union in the framework of the project entitled "Integrated understanding of Seismicity, using innovative Methodologies of Fracture mechanics along with Earthquake and non-extensive statistical physics-Application to the geodynamic system of the Hellenic Arc. "SEISMO FEAR HELLARC", (MIS 380208).

\section{References}

Algermissen, S.T., Perkins, D.M., Ishewood, W., Gordon, D., Reagor, G. and Howard, C., 1976. Seismic risk evaluation of the Balkan region, Proc. of the Sem. on Seismic Zoning Maps, UNESCO, Skopje, II, 172-240.

Atkinson, G.M. and Boore, D.M., 2003. Empirical ground-motion relations for subduction zone earthquakes and their application to Cascadia and other regions, BSSA, 93, 1703-1729.

Drakopoulos, J. and Stavrakakis, G., 1988. Energy flux, seismic moment and their influence on seismic hazard analysis, Proc. Intern. Symp. on: Seismic Zoning, Canton CHINA, 401-410.

Galanopoulos, G.A. and Delibasis, N., 1972. Map of maximum observed intensities in Greece, period 1800-1970, Athens.

Gumbel, E.J., 1958. Extreme value statistics, Columbia Univ. Press, New York, 375 pp.

Gutenberg, B. and Richter, C.F., 1944. Frequency of earthquakes in California, Bull. Seism. Soc. Am., 34, 185-188.

Hatzidimitriou, P.M., Papadimitriou, E.E., Mountrakis, D.M. and Papazachos, B.C., 1985. The seismic parameter $\mathrm{b}$ of the frequency-magnitude relation and its association with the geological zones in the area of Greece, Tectonophysics, 120, 141-151.

Koutrakis, S.I., Margaris, V.N., Koliopoulos, P.M. and Karakaisis, G.F., 1999. New trends in seismic hazard evaluation in Greece, Abstract Volume, IUGG 99, Birmingham U.K.

Koutrakis, S.I., Karakaisis, G.F. and Margaris, V.N., 2002. Seismic hazard in Greece based on different strong motion parameters, Journal of Earthquake Engineering, 6(1), 75-109.

Makropoulos, K.C. and Burton, P.W., 1985. Seismic Hazard in Greece: I Magnitude recurrence, Tectonophysics, 117, 205-257.

Margaris, B. and Papazachos, B., 1994. Implication of the azimuthal variation of seismic intensities in seismic hazard assessment, Proc. XXIV Gen. Ass. ESC, Athens, Greece, Sept. 19-24, Vol. III, 1718-1727.

McGuire, R.K., 1976. EQRISK: FORTRAN computer program for seismic risk analysis, U.S. Geol. Surv., Open file rep. No 76-67, 90 pp.

Mountrakis, D., Papazachos, C. and Thomaidou, E., 2010. Seismotectonic Map of Greece, Publ. Lesvos Petrified Forest Museum.

Papaioannou, Ch.A., 1984. Attenuation of seismic intensities and seismic hazard in Greece, $\mathrm{PhD}$ thesis University of Thessaloniki, 200 pp. (in Greek).

Papaioannou, Ch.A. and Papazachos, B.C., 2000. Time-independent and time-dependent seismic hazard in Greece based on seismogenic sources, Bull. Seism. Soc. Am., 90, 22-33.

Papazachos, B.C., 1980. Seismicity rates and long term earthquake prediction in the Aegean area, Quaterniones Geodaesiae, 3, 171-190. 
Papazachos, B.C., 1990. Seismicity of the Aegean and surrounding area. Tectonophysics, 178, 287-308.

Papazachos, B.C. and Papaioannou, Ch.A., 1993. Long-term earthquake prediction in the Aegean area based on a time and magnitude predictable model, Pageoph., 140, 593-612.

Papazachos, B.C., Papaioannou, Ch.A., Margaris, V.N. and Theodulidis, N.P., 1993. Regionalization of seismic hazard in Greece based on seismic sources, Natural Hazards, 8, 1-18.

Papazachos, B.C., Mountrakis, D.M., Papazachos, C.B., Tranos, M.D., Karakaisis, G.F. and Savvaidis, A.S., 2001. The faults that caused the known strong earthquakes in Greece and surrounding areas during 5th century B.C. up to present, Proc. 2nd Conf. Earthquake Eng. and Eng. Seism., 2-30 September 2001, Thessaloniki, Greece, 1, 17-26 (in greek).

Papazachos, B.C., Comninakis, P.E., Scordilis, E.M., Karakaisis, G.F. and Papazachos, C.B., 2010. A catalogue of earthquakes in the Mediterranean and surrounding area for the period 19012010, Publ. Geophys. Laboratory, University of Thessaloniki.

Papoulia, J.E. and Stavrakakis, G.N., 1990. Attenuation laws and seismic hazard assessment, Natural Hazards, 3, 49-58.

Papoulia, J. and Slejko, D., 1992. Cautious neotectonic hypotheses for assessing the seismic hazard in Northeastern Italy, Natural Hazards, 5, 249-268.

Papoulia, J., Lykousis, V. and Sakellariou, D., 1998. Neotectonic activity and seismic hazard in central Greece, Bollettino di Geofisica Teorica et Applicata, 39(2), 113-124.

Shebalin, N.V., Reisner, G.I., Dfrumea, A.V., Aptekman, J.V., Sholpo, V.N., Stepaneks, N.Y. and Zacharova, A.J., 1976. Earthquake origin zones and distribution of maximum expected seismic intensity for the Balkan region, Proc. Sem. Seismic Zoning Maps, UNESCO, Skopje 1975, 2, 68-171.

Skarlatoudis, A.A., Papazachos, C.B., Margaris, B.N., Theodulidis, N., Papaioannou, Ch., Kalogeras, I., Scordilis, E.M. and Karakostas, V., 2003. Empirical peak ground motion predictive relations for shallow earthquakes in Greece, Bull. Seism. Soc. Am., 93, 2591-2603.

Skarlatoudis, A.A., Papazachos, C.B., Margaris, B.N., Theodulidis, N., Papaioannou, Ch., Kalogeras, I., Scordilis, E.M. and Karakostas, V., 2007. ERRATUM: Empirical peak ground motion predictive relations for shallow earthquakes in Greece, Bull. Seism. Soc. Am., 97.

Skarlatoudis, A.A., Papazachos, C.B., Margaris, B.N., Ventouzi, Ch., Kalogeras, I. and the EGELADOS group 2013. Ground motion prediction equations of intermediate-depth earthquakes in the Hellenic arc, southern Aegean subduction area, BSSA, 103, 1952-1968.

Stavrakakis, G. and Tselentis, G.-A., 1987. Bayesian probabilistic prediction of strong Earthquakes In The Main Seismogenic Zones Of Greece, Bolletino Di Geofisica Teorica Ed Applicata, XXIX, 1-13.

Stavrakakis, G.N. and Drakopoulos, J., 1995. Bayesian probabilities of earthquake occurrences in Greece and surrounding areas, Pageoph., 144, 307-319.

Theodulidis, N. and Papazachos, B., 1992. Dependence of strong ground motion on magnitudedistance, site geology and macroseismic intensity for shallow earthquakes in Greece: I, Peak horizontal acceleration, velocity and displacement, Soil Dyn. \& Earth. Eng., 11, 387-402.

Tsapanos, T.M., Papadopoulos, G.A. and Galanis, O.G., 2003. Time independent seismic hazard analysis of Greece deduced from Bayesian statistics, Natural Hazards and Earth System Sciences, 3, 129-134.

Tselentis, G.A. and Danciu, L., 2010. Probabilistic seismic hazard assessment in Greece-Part 1: Engineering ground motion parameters, Nat. Hazards Earth Syst. Sci, 10, 25-39.

Vamvakaris, D., Papazachos, C., Papaioannou, Ch., Skordilis, E. and Karakaisis, G., 2008. Timeindependent and time-dependent seismic hazard study using synthetic catalogues, The $3^{\text {nd }}$ National Conference of Earthquake Engineering and Engineering Seismology, Athens- Greece.

Vamvakaris, D.A., 2010. Contribution to the study of time-dependent seismicity and seismic hazard, PhD Thesis University of Thessaloniki, 503 pp. (in Greek).

Vamvakaris, D.A., Papazachos, C.B., Papaioannou, C., Scordilis, E.M. and Karakaisis, G.F., 2015. A detailed seismic zonation model for shallow earthquakes in the broader Aegean area, Nat. Hazards Earth Syst. Sci. (accepted).

Weichert, D.H. and Milne, W.G., 1979. On Canadian methodologies of probabilistic seismic risk estimation, Bulletin of the Seismological Society of America, 69, 1549-1566. 